\title{
Research into mental health supported accommodation - desperately needed but challenging to deliver
}

\author{
Helen Killaspy and Stefan Priebe
}

\section{Summary}

Around 100000 people live in mental health supported accommodation in England, at considerable cost to the public purse, but there is little evidence to guide investment in the most effective models. We consider the various barriers to research in this field and offer suggestions on how to address them.
Keywords

Rehabilitation; outcome studies; qualitative research; randomised controlled trial.

\section{Copyright and usage}

(C) The Authors 2020.
Helen Killaspy (pictured) is a rehabilitation psychiatrist and researcher who leads national and international studies that aim to enable recovery for people with complex psychosis. Stefan Priebe is a psychologist and psychiatrist who leads research programmes that investigate how social interventions can reduce mental distress.

\section{Housing and mental illness}

The United Nations declared adequate housing a universal human right $^{1}$ and having a safe and stable home is widely regarded as essential to an individual's health. However, this right is not implemented universally and people with mental illnesses are among the vulnerable and disadvantaged groups at particular risk of inadequate housing or homelessness. A large proportion of rough sleepers, whose number has doubled since 2010, have mental illnesses: approximately $13 \%$ have some form of psychosis (10 times the rate in the general population) and around two-thirds have substance misuse problems. ${ }^{2}$ Often these coexist, leading to serious physical health problems and premature mortality.

\section{Supported accommodation services}

Health and social services are responsible for addressing the needs of people with mental health conditions and housing services can also provide a platform for support, therapy and rehabilitation. Indeed, for individuals with more complex needs, supported accommodation is acknowledged as a key component of the mental health rehabilitation care pathway, assisting people to gain the skills and confidence to manage with less support over time. ${ }^{3}$ Supported accommodation services are usually staffed by support workers rather than mental health professionals, with specialist clinical input from visiting community mental health teams provided by the statutory National Health Service (NHS). In England, there are three main types of mental health supported accommodation: residential care homes that comprise communal facilities, staffed $24 \mathrm{~h}$ a day, providing meals, cleaning, laundry, supervision of medication and activities, and where residence is not time limited; supported housing services that provide shared or individual, selfcontained, time-limited tenancies, with staff on-site up to $24 \mathrm{~h}$ a day to assist the person to gain skills to move on to less supported accommodation; and floating outreach services that provide visiting support of a few hours per week to people living in permanent, self-contained, individual tenancies, with the aim of reducing support over time to zero. ${ }^{3}$

\section{Costs of supported accommodation services}

Across the country, it is estimated that around 30000 adults with mental health conditions live in a residential care home, around 29500 in supported housing (5\% of all people in supported housing) and around 24000 receive a specialist mental health floating outreach service. The cost of these services runs to hundreds of millions of pounds per year; the average weekly cost per person of floating outreach is $£ 107$, supported housing is $£ 317$ and residential

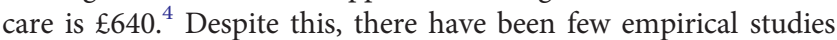
evaluating the effectiveness of these services and no trials comparing models. Recently, the Care Quality Commission raised concerns about the number of people with complex mental health problems experiencing lengthy admissions in so called 'locked rehabilitation units', usually provided by the independent sector, many miles from the person's home and at a total cost to the NHS, which has been estimated at over $£ 500 \mathrm{~m}$ per year. ${ }^{5}$ Some supported accommodation providers have started to implement hybrid models that include both support workers and clinical staff to facilitate patients' discharge from in-patient rehabilitation units. Although these may represent a more efficient use of resources and potentially reflect the political desire for greater integration of the different sectors providing services (statutory health and social care, voluntary and private sectors), logistical problems have been reported, which may pose serious risks to client and staff safety. These include a lack of clarity about decision-making owing to split management systems, and difficulties accessing clinical records on-site owing to incompatible computer systems. These new models also lack robust evaluation.

\section{Evidence for mental health supported accommodation in England}

From 2012 to 2017 we conducted a programme of research into mental health supported accommodation across England, funded by the National Institute of Health Research. ${ }^{4}$ We found that people living in residential care had the highest level of needs, and those in supported housing and floating outreach had similar levels. After adjusting for differences in clinical characteristics, those who used supported housing services had the greatest autonomy but, along with those who used floating outreach services, were 
much more likely to be a victim of crime than those living in residential care $(>20 \% v .4 \%)$. It therefore appears that as people move to more independent accommodation, their vulnerability increases. We followed 586 individuals and found that $41 \%$ were able to manage with less support at 30 months of follow-up, but there were large differences between service types $(10 \%$ of those in residential care, $39 \%$ in supported housing and $67 \%$ of those receiving floating outreach at recruitment achieved this). These figures highlight the unrealistic targets that these services have to work to; most supported housing services are commissioned to 'move people on' within 2 years. This results in a large number of individuals whose needs remain high being moved to another supported accommodation service providing a similar level of support, simply to meet this key performance indicator. This is clearly unhelpful, unnecessary and, frankly, inhumane.

\section{Comparing models of supported accommodation through a randomised controlled trial}

Considering the lack of evidence on the effectiveness of different models, we believed that a randomised controlled trial comparing supported housing and floating outreach was required. We drew from the analogy of vocational rehabilitation where several trials have successfully randomised participants to either 'train and place' (a more conventional approach of stepwise work related rehabilitation, where the person progresses from 'sheltered' settings to mainstream employment) or 'place and train' (where the individual is directly placed into independent employment with flexible support provided as needed - this model is known as individual placement and support). In a similar fashion, we conducted a feasibility trial to compare supported housing and floating outreach services. Because few differences have been found in the support delivered by these two models, the question is whether the current system, whereby individuals graduate from supported housing to floating outreach services, is really necessary or whether individuals might be able to move directly to a permanent tenancy with flexible intensity floating outreach support. The latter would have the advantage of reducing the number of moves an individual has to make. However, recruitment and randomisation were extremely difficult: of 1432 people screened, only 8 were randomised. Barriers included staff and patient concerns about the type of supported accommodation being decided at random, and clinicians' perceived lack of equipoise in the two models being compared; most felt that individuals needed to first live in supported housing before 'stepping down' to floating outreach services. We concluded that trials comparing existing models of supported accommodation in England were not feasible or would end up with a highly selective sample preventing any generalisation of the findings. In a context where new models of supported accommodation are springing up, the absence of evidence presents a major problem for service planners.

\section{Barriers to conducting trials in this field}

One can only speculate as to why randomisation is possible to different models of vocational rehabilitation, but not to different models of supported accommodation. First, a possible explanation is that where a person lives may be seen as more fundamental to life than gaining employment, and health service staff may feel more responsible for adverse events/risks arising in the home compared with the workplace, thus making randomisation for a research study of supported accommodation unacceptable. Second, arranging accommodation requires more processes and approvals than arranging employment, involving various individuals, agencies and decision-making panels, and this process (which varies substantially across local authorities) multiplies the probability that someone in the decision chain raises concerns and vetoes the potential randomisation of an individual. Finally, even if the approval processes could be streamlined, it is challenging to ensure adequate availability of different types of supported accommodation for randomised individuals to move to - allocation is, understandably, heavily influenced by vacancies in local supported accommodation.

\section{The way forward}

What is the way forward, when - at least in the current context in the UK - randomised controlled trials comparing different approaches to housing do not appear feasible? We could decide to leave the expensive and important field of housing services for people with mental illnesses an evidence-free area, yet it would be ethically and practically unacceptable to ignore these services in research just because they are difficult to study. Thus, different methods to evaluate them have to be found. Working with policy makers and service providers to collect and publish data on all services in the country about the type of residents they accept, what exactly is being provided, how long they stay and what their outcomes are in terms of social and everyday function, experiences and quality of life may be a first step. This would not require sophisticated research study designs but could provide a starting point for more specific longitudinal studies. We could also conduct more qualitative research. However, although our recent systematic review of the qualitative evidence identified a large range of structural, process, relational and contextual factors that influenced patients' experiences, we found no clear differences in the culture and content of care delivered by different types of supported accommodation. ${ }^{4} \mathrm{~A}$ further idea would be to use the considerable international variation in models as a type of natural experiment for comparing costs and outcomes. Whatever research methods are found to be feasible, providing better evidence for which type of housing support is beneficial for different groups of people with mental illnesses remains a major challenge to the research community.

\footnotetext{
Helen Killaspy (D), MBBS, PhD, FRCPsych, Division of Psychiatry, University College London; and Honorary Consultant in Rehabilitation Psychiatry, Rehabilitation and London; and Honorary Consultant in Rehabilitation Psychiatry, Rehabilitation and
Recovery Services, Camden and Islington NHS Foundation Trust, UK; Stefan Priebe Dipl. Psych., Dr. med. habil., FRCPsych, Unit for Social and Community Psychiatry, World Health Organization Collaborating Centre for Mental Health Services Development, Queen Mary University, UK

Correspondence: Helen Killaspy. Email: h.killaspy@ucl.ac.uk

First received 7 Jan 2020, final revision 19 Feb 2020, accepted 16 Mar 2020
}

Declaration of interest
None.
ICMJE forms are in the supplementary material, available online at https://doi.org/10.1192/
bjp.2020.74.

\section{References}

1 Office of the United Nations High Commission for Human Rights. The Right to Adequate Housing. Fact Sheet No. 21/Rev.1. United Nations, 2009. ISSN 10145567

2 Ministry of Housing, Communities and Local Government. Rough Sleeping Statistics Autumn 2018, England, Revised. The Stationery Office, 2019 (https:// assets.publishing.service.gov.uk/government/uploads/system/uploads/ attachment_data/file/781567/Rough_Sleeping Statistics_2018 release.pdf). 
3 Joint Commissioning Panel for Mental Health. Guidance for Commissioners of Rehabilitation Services for People with Complex Mental Health Needs. Practical Mental Health Commissioning. Joint Commissioning Panel for Mental Health, 2016 (https://www.jcpmh.info/wp-content/uploads/jcpmh-rehab-guide.pdf).

4 Killaspy H, Priebe S, King M, Eldridge S, Mccrone P, Shepherd G, et al Supported Accommodation for People with Mental Health Problems: the
QUEST Research Programme with Feasibility RCT (Programme Grants for Applied Research, No. 7.7. NIHR Journals Library, 2019 (https://www.ncbi.nlm. nih.gov/books/NBK546971/)

5 Care Quality Commission (CQC). The State of Care in Mental Health Services 2014 to 2017. CQC, 2018 (https://www.cqc.org.uk/publications/major-report/ state-care-mental-health-services-2014-2017).

\section{psychiatry in pictures}

\section{Robert Hooke's Bethlem Hospital of 1676: an architectural wonder}

\section{R.H.S. Mindham (iD}

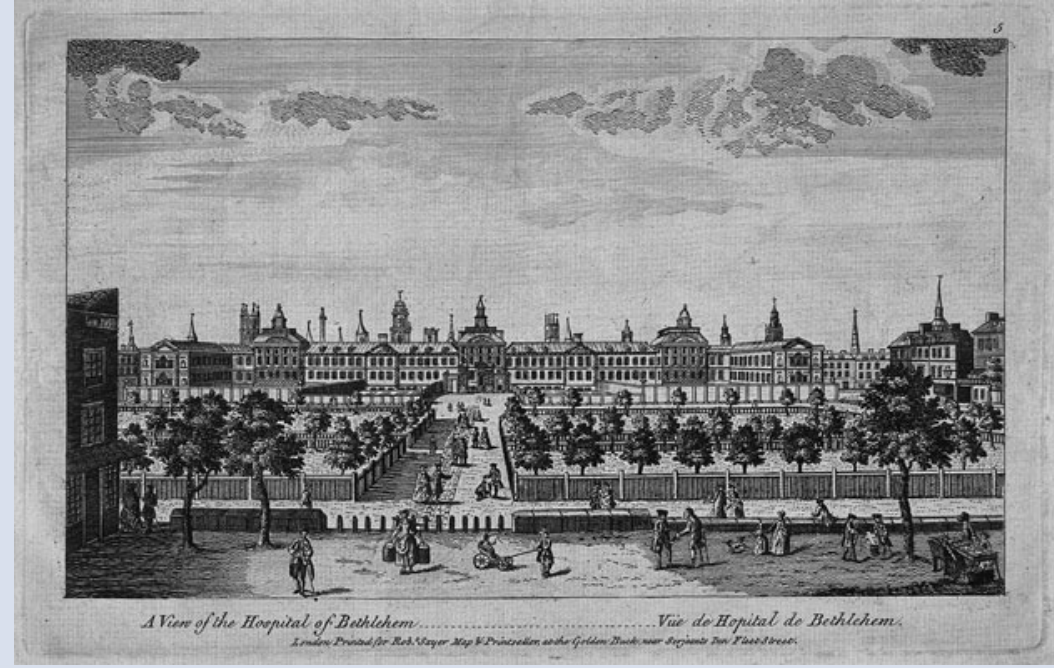

Fig. 1 Bethlem Hospital (c. 1740). Wellcome Collection, (CC BY 4.0)

The Priory of Saint Mary of Bethlehem was established in 1247 as an outpost of the mother church in Palestine and lay just to the north of the walls of the City of London on land donated by Simon FitzMary. Like many religious communities, the Priory cared for the sick and by 1400 had come to specialise in the care of the mentally ill. On dissolution of the monasteries the Priory became the property of the Crown and one of the five 'Royal Hospitals', with Saint Bartholomew's, Saint Thomas', Bridewell and Christ's Hospital. In 1546 the Lord Mayor of London, Sir John Gresham, petitioned the Crown to allow the administration of Bethlem to pass to the City; this was granted.

The Priory was accommodated in dilapidated buildings and in 1674 the authorities sought a new building. They engaged Robert Hooke to prepare plans. Professor of Geometry at Gresham College and curator of experiments to the Royal Society, Hooke had worked on major buildings with Wren and Hawksmoor (including the Monument) and had himself designed the Royal college of Physicians. Most recently he had surveyed a part of London after it had been destroyed by the fire of 1666.

The new hospital was designed to accommodate 136 patients on two floors, with equal provision for men and women. The site backed onto London Wall close to the church of All Hallows. Hooke adopted a single-pile method of construction to ensure good ventilation. This choice led to a long narrowbuilding. He combined the monastic layout of a cell for each patient with a broad corridor similar to the galleries of grand houses. Each cell had a small barred window facing south with no glazing. The galleries faced north and were glazed. The last in Hogarth's series of paintings A Rake's Progress ('In the Madhouse') shows how the galleries were used. In creating the 'gallery ward', Hooke had introduced an arrangement that was to be used in the design of mental hospitals for more than 200 years.

Externally, the building was in the baroque style and almost 600 feet in length. The galleries ran the full length of the building but were interrupted by grills. The central administrative block and the end pavilions were faced in stone and were advanced. The building was decorated with pilasters, balustrades, viewing platforms, swags and cupolas, giving an impression of considerable grandeur reminiscent of a palace; this gave rise to mocking comments comparing the hospital to the Palace of Versailles and questioning whether this was a wise provision for the accommodation of lunatics. Statues of 'raving and melancholy madness', by the Danish sculptor Cibber, stood on top of the gate posts, announcing the building's purpose.

Between 1723 and 1735 wings in the Palladian style were added at each end of the building. These double-banked wards were less satisfactory than those opening onto a gallery. Figure 1 shows the enlarged hospital with, in the background, the towers and spires of new City churches designed by Wren and his associates. As time went by the building suffered from neglect and from the marshy ground on which it stood. After much negotiation and a subsidy from the government the hospital moved to a new building at St George's Fields, Lambeth, in 1815. The new hospital, a part of which is now the Imperial War Museum, was remarkably like the one it replaced.

Copyright @ The Author 2021. Published by Cambridge University Press on behalf of the Royal College of Psychiatrists 